\title{
Propofol Versus Combined Propofol \&Dexmedetomidine for Conscious Sedation in Colonoscopy
}

\author{
Amira I.F. Lashin ${ }^{\text {* }}$, Gehan A. Eldesoky ${ }^{1}$, Alshaimaa M.M. Eid ${ }^{2}$, Sammar A. Kasim ${ }^{3}$ \\ ${ }^{1}$ Department of Anesthesiology and Intensive Care, Faculty of Medicine, Al-Azhar University. Cairo, Egypt. \\ ${ }^{2}$ Department of hepatology, gastroenterology, and infectious diseases, Faculty of Medicine, Al-Azhar University. Cairo, \\ Egypt. \\ ${ }^{3}$ Department of internal medicine, Faculty of Medicine, Al-Azhar University. Cairo, Egypt. \\ * Correspondence: dr.merolashin2007@gmail.com. Tel: 01002218191
}

\begin{abstract}
Article history: Received: 25-11-2021
Revised:31-12-2021

Accepted: 15-1-2022

Abstract: Colonoscopy is an endoscopic procedure that examines the mucosa of the large intestine and distal terminal ileum for histopathological sampling and therapeutic procedures. Aim of the work: Comparing propofol \& dexmedetomidine effects as conscious sedation in colonoscopy. Methods: Forty patients of both sexes candidates for colonoscopy were randomized to (D group \& P group) each one included 20 patients: D Group: Dexmedetomidine was given as an initial loading dosage of $1 \mu \mathrm{g} / \mathrm{kg}$ i.v over ten minutes then received propofol $0.5 \mathrm{mg} / \mathrm{kg}$, then a continuous I.V. dexmedetomidine infusion $(0.2-0.8) \mu \mathrm{g} / \mathrm{kg} / \mathrm{h}$ was started until the procedure completed. P Group: The intravenous loading dose of propofol $2 \mathrm{mg} / \mathrm{kg}$ was given, then a continuous infusion of propofol $25-100 \mu \mathrm{g} / \mathrm{kg} / \mathrm{min}$ was started until the procedure was completed. Results: The level of sedation was assessed using the Ramsay Sedation Score (RSS) showed a significant increase in the P group (2-2) compared to the D group activity (1-2) throughout 1-hour post-operatively. After $5 \mathrm{~min}$ of the procedure heart rate significantly decreased in group D then it became non-significant during the remaining time. The oxygen saturation $\%$ values showed a significant reduction in the $\mathrm{P}$ group $($ mean $95.45 \pm 2.70)$ at 5 min of the procedure then it became non-significant during all remaining time. Although Bradycardia was more significantly higher in the D group, hypotension and respiratory complications were more significant higher in the $\mathrm{P}$ group. Also, the endoscopist was satisfied in the D group. Conclusion: In patients undergoing colonoscopy, dexmedetomidine combined with a low dose of propofol resulted in greater conscious sedation and adequate endoscopist satisfaction than propofol alone.
\end{abstract}

Keywords: Dexmedetomidine, propofol, conscious sedation, and colonoscopy

This is an open access article distributed under the CC BY-NC-ND license https://creativecommons.org/licenses/by/4.0/

\section{INTRODUCTION}

Colonoscopy is the "gold standard" for detecting and removing colorectal cancer (CRC) and its precursors early on ${ }^{(1)}$. Colonoscopy is a slightly painful procedure that needs conscious sedation. Although some people can undergo a colonoscopy treatment without sedation or analgesics, most patients find it to be a painful procedure. The most common type of sedation is conscious sedation. Several medications as opioids, ketamine, and midazolam have been used alone or with propofol as a combination and have been linked to adverse effects as respiratory depression (2). Dexmedetomidine is considered a potent highly selective $\alpha_{2}$-adrenergic receptors (AR) agonist as these receptors have been found in the central \& peripheral nervous system (spinal cord), also found in the platelets and many organs such as the liver, pancreas, kidneys, and eyes. Depending on the location of the receptors, they regulate different physiological responses.
Neuronal firing is inhibited when these receptors in the brain and spinal cord are stimulated, resulting in drowsiness, analgesia, hypotension, and bradycardia ${ }^{(3)}$. Dexmedetomidine is indicated for conscious sedation patients which have been safely used in different procedures like colonoscopy, transesophageal echocardiography, awake carotid endarterectomy, shock wave lithotripsy, or vitreoretinal surgery ${ }^{(4)}$. In addition, it decreases the stress-induced sympathetic response, protects the heart from myocardial ischemia, and has few side effects on the respiratory system. It is a medication of choice in conscious sedation because of these favorable benefits ${ }^{(5)}$. Dexmedetomidine has a distribution half-life of 6 minutes in people at doses of $0.2-0.7 \mathrm{mcg} / \mathrm{kg} / \mathrm{h}$ intravenous infusion, indicating that it is rapidly dispersed and has a 2-hour elimination halflife. Propofol is considered a common sedative-hypnotic used in one-day surgeries because it has a rapid onset and recovery time. It has been reported to produce dose-

Cite this article: Lashin, A., Eldesoky , G., Eid, A., Kasim, S. Propofol Versus Combined Propofol \&Dexmedetomidine for Conscious Sedation in Colonoscopy.Azhar International Journal of Pharmaceutical and Medical Sciences, 2022; 2 (1):117 -123. doi: 10.21608/aijpms.2022.107855.1098 DOI : 10.21608/aijpms.2022.107855.1098 
dependent respiratory depression, which may be aggravated when combined with opioids, requiring resuscitation efforts ${ }^{(6,7)}$.

Propofol, either alone or with midazolam and/or fentanyl as a combination, is one of the most commonly utilized sedative regimens for GI endoscopic (GIE) procedures. However, combining sedatives and/or analgesics with propofol may increase the risk of side effects. Dexmedetomidine provides a level of sedation that allows natural sleep and communication while also lowering analgesic requirements, improving respiratory safety, and maintaining hemodynamic stability ${ }^{(8)}$. Although deep sedation with propofol is associated with greater patient satisfaction, faster post-procedure recovery time, and in some studies shorter procedure time, the clinically significant outcomes, such as cecal intubation rates and adenoma detection rates, are not improved. Using anesthesia during colonoscopy may be associated with increased complications, including perforation following polypectomy, bleeding, abdominal pain, and complications associated with anesthesia $^{(9)}$.

Here, we compared the effects of intravenous propofol versus combined propofol $\&$ dexmedetomidine as conscious sedation in colonoscopy.

The primary outcome of this study was to assess the level of sedation preoperatively, intraoperatively, and postoperatively using the Ramsay Sedation Score (RSS).

The secondary outcomes were to identify any changes in vital signs (heart rate, MAP, and oxygen saturation $\%$ values) throughout the colonoscopy with any apparent complications such as bradycardia, hypotension, or respiratory complication. Also, Endoscopist satisfaction was recorded.

\section{METHODS}

This prospective, randomized, double-blinded study was carried out in the department of hepatogastroenterology and infectious diseases department at Al-Zahra university hospital after receiving institutional approval from the hospital's ethical committee under the registration number (2021111130), and signed informed consent was collected from all patients

Inclusion criteria included: Forty adult patients of both sexes, ranging in age from 25 to 60 years old, with ASA physical status I, II, or III who were scheduled for a colonoscopy. The patients were divided into two groups (D group and $\mathrm{P}$ group) using computer-generated randomization.

Exclusion criteria included: Patients with psychological illnesses, patients with a history of alcoholism or drug misuse, patients with severe cardiac or respiratory diseases, pregnant women, lactating women, drug sensitivity, or overweight (BMI>35).

History, clinical examination, and basic investigation were all part of the patients' pre-operative evaluation. The day before a colonoscopy, all the patients needed to clean out their colon and were informed not to eat solid food and were allowed to drink clear liquids or plain water. Also, they were taken a laxative the night before and in the morning of the procedure. Patients from two groups were kept nil per oral for clear fluids \& water 2 hours before the procedure. Overnight and on the morning of the colonoscopy, all patients were given $150 \mathrm{mg}$ of ranitidine tablet. The patients were taken to the preoperative room where an intravenous (i.v) connection was established using an 18 or $20 \mathrm{G}$ cannula. The patients were transferred to the procedure room, where ECG was used to continue monitoring the patient's heart rate, as well as non-invasive monitoring of blood pressure using (Drager monitor vista 120 Germany or vista XL-USA monitor). A nasal oxygen catheter attached to an anesthetic machine was used to deliver oxygen (Drager Primus or Drager pulse USA). Patients were given ringer lactate or normal saline fluids based on their body weight. Then, according to each group's technique, the induction of anesthesia began:

D Group (patients had receiving dexmedetomidine): They received intravenous dexmedetomidine as an initial loading dosage of $1 \mu \mathrm{g} / \mathrm{kg}$ over ten minutes then received propofol $0.5 \mathrm{mg} / \mathrm{kg}$. After that a continuous i.v dexmedetomidine infusion $(0.2-0.8)$ $\mu \mathrm{g} / \mathrm{kg} / \mathrm{h}$ was started until the procedure is completed.

P Group (patients had receiving propofol): They received an intravenous loading dose of propofol 2 $\mathrm{mg} / \mathrm{kg}$, then a continuous infusion of propofol 25-100 $\mathrm{mg} / \mathrm{kg} / \mathrm{min}$ was started until the procedure was completed. The time of the procedure was ranged from $20 \mathrm{~min}$ up to $45 \mathrm{~min}$.

\section{Measured parameters: -}

The level of sedation was assessed preoperatively, intraoperatively, and postoperatively using the Ramsay Sedation Score (RSS), which ranged from 1-6 points (table 1).

Heart rate, MAP, and oxygen saturation \% values were taken as a baseline. Throughout the colonoscopy, heart rate and oxygen saturation were continuously monitored. Intraoperatively, MAP was monitored every 5 minutes for the first 30 minutes, then every 15 minutes until the procedure was completed. Also, Endoscopist satisfaction was recorded. Any complications as hypotension (defined as MAP $<20 \%$ of preoperative value) was managed with a bolus of fluid and bolus of 6 $\mathrm{mg}$ i.v. injectable ephedrine. IV atropine $0.01 \mathrm{mg} / \mathrm{kg}$ was used to treat bradycardia (heart rate $50 / \mathrm{min}$ ). Manual ventilation was used to treat apnea or bradypnea (respiratory rate less than 10/min). In the recovery room, all patients were given oxygen via a face mask at a rate of $5 \mathrm{~L} / \mathrm{min}$ for 2 hours while their heart rate, blood pressure, and oxygen saturation percentage were monitored.

The sample size was calculated on MedCalc program version 11.3.0.0 and according to a previous study done by Tanriverdi et al. (2019) who compared in his study between dexmedetomidine vs propofol during hysteroscopic surgery and found that pain score by 
visual analog scale was higher in propofol group 5.0 \pm 1.9 than dexmedetomidine group $1.9 \pm 1.8$ with a mean difference of 3.1 and adjusting the confidence interval to $95 \%$; the power of the test to $90 \%$ and the ratio Table 1: Ramsay Sedation Score between groups to $1: 1$. the minimum sample size needed for this study was found 8 patients per group (a total of 16 patients in the two studied groups).

\begin{tabular}{lc}
\hline LEVEL OF ACTIVITY & POINTS \\
\hline Patient anxious, agitated or restless & 1 \\
\hline Patient cooperative, orientated and tranquil & 2 \\
\hline Patient responding only to verbal commands & 3 \\
\hline $\begin{array}{l}\text { Patient with brisk response to light glabella tap or loud } \\
\text { auditory stimulus }\end{array}$ & 4 \\
\hline $\begin{array}{l}\text { Patient with sluggish response to light glabella tap or loud } \\
\text { auditory stimulus }\end{array}$ & 5 \\
\hline $\begin{array}{l}\text { Patient with no response to light glabella tap or loud } \\
\text { auditory stimulus }\end{array}$ & 6
\end{tabular}

\section{Statistical Evaluation}

Data were gathered, reviewed, coded, and entered into the Statistical Package for Social Science (IBM SPSS Released 2015, Version 23.0. Armonk, New York: IBM Corporation). When parametric data were presented as mean, standard deviations, and ranges, and when nonparametric data were presented like median with interquartile range (IQR), qualitative variables were presented like numbers and percentages. The independent t-test was used to compare two independent groups with quantitative data and parametric distribution, while the Mann-Whitney test was used for non-parametric data; the Chi-square test was used to compare groups with qualitative data. The confidence interval was set to $95 \%$ and the margin of error accepted was set to $5 \%$. So, the p-value was considered significant at the level of $<0.05$.

\section{RESULTS}

The difference among the two groups was not statistically significant $(\mathrm{P}>0.05)$ in terms of age, sex, duration of surgery \& ASA physical status (table2). As regard heart rate value, the difference among the two groups was not statistically significant. $(\mathrm{P}>0.05)$ at all measured times, except at $5 \mathrm{~min}$ after the induction, the D group experienced a significant decrease. (Mean 57.1 \pm 6.93 with range $49-72 \mathrm{~b} / \mathrm{min}$ ) than $\mathrm{P}$ group (mean $65.00 \pm 12.51$ with range $49-85 \mathrm{~b} / \mathrm{min}$ ) (figure 1). The difference among the two groups was not statistically significant for MAP $(\mathrm{P}>0.05)$ at all measured times, except at $10 \mathrm{~min}$ there was a significant decrease for MAP in the $\mathrm{P}$ group (mean73.40 \pm 5.89 with range 65 $104 \mathrm{mmHg}$ ) than D group (mean $80.70 \pm 11.92$ with range $65-95 \mathrm{mmHg}$ ) (figure 2). Group $\mathrm{P}$ had a significant decrease in oxygen saturation (but no desaturation) (mean $95.45 \pm 2.70)$ with range $(92-100$ $\%)$ than group D (mean $97.55 \pm 3.03$ ) with range (92$100 \%$ ), at $5 \mathrm{~min}$ of the procedure then it became non- significant during all remaining time (figure 3 ). In the preoperative, and 2 hours postoperative period, there was no statistically significant difference among both groups as regarded RSS activity where median IQR (1.5 with ranged 1-2). Also, in the intraoperative period, there was no statistically significant difference among both groups where median IQR (3 ranged 2-4 in both groups). But at one-hour postoperative, there was a significant increase in RRS activity in the $\mathrm{P}$ group where median IQR (2 with ranged 2-2) than D group where median IQR (2 with ranged 1-2) (table 3). There were 10 patients $(50 \%)$ in the D group who developed bradycardia (heart rate of 50 beats per minute) compared to 3 patients $(15 \%)$ in the $\mathrm{P}$ group, which was significantly higher in the $\mathrm{D}$ group compared to the $\mathrm{P}$ group (P-value 0.05). The decrease in heart rate was managed by (IV $0.01 \mathrm{mg} / \mathrm{kg}$ atropine). As regarding hypotension (MAP $<20 \%$ of preoperative value) which occurred in 4 patients $(20 \%)$ in the D group and 11 patients $(55 \%)$ in the $\mathrm{P}$ group, when compared to group $\mathrm{P}$, there was a significant decrease in group $\mathrm{D}(\mathrm{P}<0.05)$. A bolus of fluid and ephedrine $6 \mathrm{mg}$ i.v. bolus was used to control the drop in MAP. Also, there was a significant decrease in the D group (2 patients $10 \%$ ) than the $\mathrm{P}$ group (8 patients 40\%) regarding respiratory complications. In our study, we compared Endoscopist satisfaction which showed no statistically significant difference among the two groups. However, the Endoscopist in group $\mathrm{P}$ was displeasing (10 patients) compared to (6 patients) in group $\mathrm{D}$ because of an increased proclivity to use rescue medication (increase propofol infusion dose) as a result of restlessness (Table 4). 
Propofol and dexmedtomidine in colonoscopy

Table 2: Demographic data in two groups

\begin{tabular}{|c|c|c|c|c|c|c|}
\hline & & Group D & Group P & Test value & P-value & Sig. \\
\hline & & 20 patients & 20 patients & & & \\
\hline \multirow[t]{2}{*}{ Sex } & Females & $14(70.0 \%)$ & $10(50.0 \%)$ & $1.667 *$ & 0.197 & NS \\
\hline & Males & $6(30.0 \%)$ & $10(50.0 \%)$ & & & \\
\hline \multirow[t]{2}{*}{ Age (years) } & Mean \pm SD & $45.70 \pm 8.49$ & $42.00 \pm 6.97$ & $1.506^{\bullet}$ & 0.140 & NS \\
\hline & Range & $30-59$ & $31-53$ & & & \\
\hline \multirow[t]{2}{*}{ Weight (kg) } & Mean \pm SD & $77.70 \pm 8.23$ & $76.10 \pm 9.18$ & $0.580^{\bullet}$ & 0.565 & NS \\
\hline & Range & $65-88$ & $64-88$ & & & \\
\hline \multirow[t]{2}{*}{ Duration of surgery (min) } & Mean \pm SD & $34.50 \pm 6.67$ & $34.50 \pm 6.67$ & $0.000^{\bullet}$ & 1.000 & NS \\
\hline & Range & $25-45$ & $25-45$ & & & \\
\hline \multirow[t]{3}{*}{ ASA } & I & $4(20.0 \%)$ & $4(20.0 \%)$ & $0.508^{*}$ & 0.776 & NS \\
\hline & II & $6(30.0 \%)$ & $8(40.0 \%)$ & & & \\
\hline & III & $10(50.0 \%)$ & $8(40.0 \%)$ & & & \\
\hline
\end{tabular}

$\mathrm{P}$ value $>0.05:$ Not significant; $\mathrm{P}$ value $<0.05$ : Significant; $\mathrm{P}$ value $<0.01$ : Highly significant

Test value $\bullet:$ Independent t-test; $*$ : Chi-square test

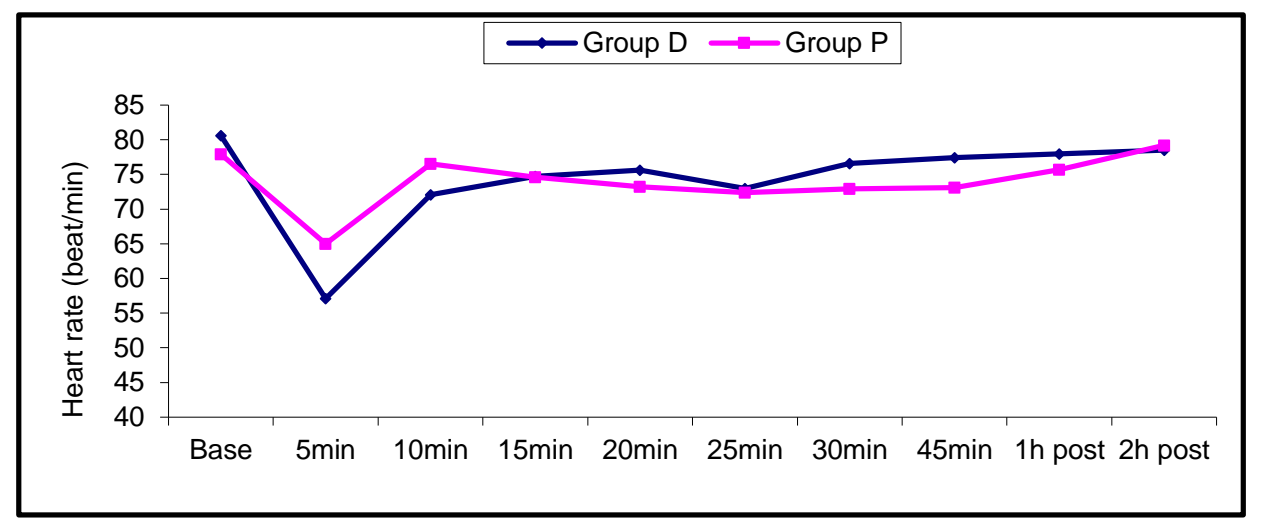

Figure 1: Heart rate changes (beat/min) in two groups

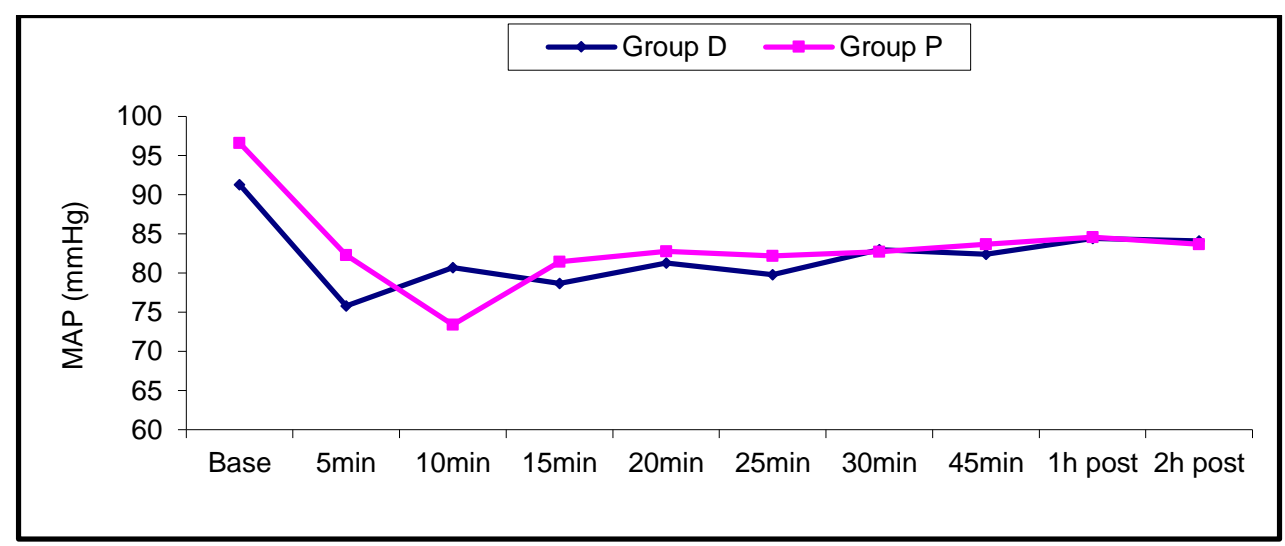

Figure 2: MAP (mmHg) changes in two groups 


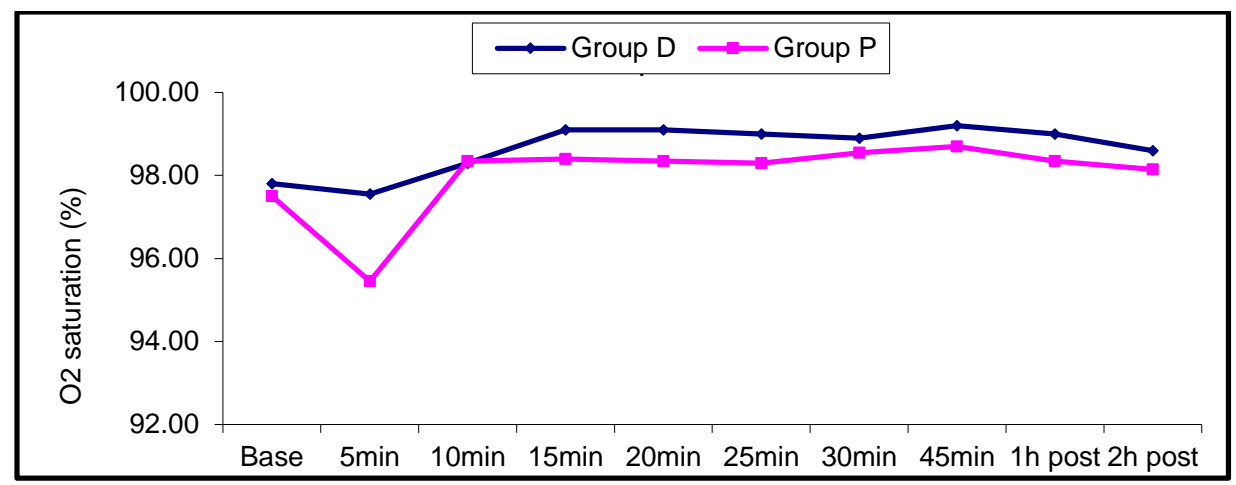

Figure 3: $\mathrm{O}_{2}$ Saturation $\%$ changes in two groups

Table 3: Comparison between two groups as regarding RSS

\begin{tabular}{|c|c|c|c|c|c|c|}
\hline \multicolumn{2}{|c|}{$\begin{array}{c}\text { Ramsey sedation score (1-6) } \\
\text { (RSS) }\end{array}$} & \multirow{2}{*}{\begin{tabular}{|c|} 
Group D \\
20 patients \\
$1.5(1-2)$ \\
\end{tabular}} & \multirow{2}{*}{\begin{tabular}{|c|} 
Group $\mathbf{P}$ \\
20 patients \\
$1.5(1-2)$ \\
\end{tabular}} & \multirow{2}{*}{$\begin{array}{c}\text { Test value } \\
0.000^{\#}\end{array}$} & \multirow{2}{*}{\begin{tabular}{|c|} 
P-value \\
1.000
\end{tabular}} & \multirow{2}{*}{$\begin{array}{r}\text { Sig. } \\
\text { NS }\end{array}$} \\
\hline \multirow[t]{2}{*}{ Preoperative } & Median (IQR) & & & & & \\
\hline & Range & $1-2$ & $1-2$ & & & \\
\hline \multirow[t]{2}{*}{ Intraoperative } & Median (IQR) & $3(3-3)$ & $3(2-4)$ & $0.000^{\#}$ & 1.000 & NS \\
\hline & Range & $2-4$ & $2-4$ & & & \\
\hline \multirow{2}{*}{ Post 1h } & Median (IQR) & $2(1-2)$ & $2(2-2)$ & $2.276^{\#}$ & 0.029 & $\mathrm{~S}$ \\
\hline & Range & $1-2$ & $1-2$ & & & \\
\hline \multirow[t]{2}{*}{ Post 2h } & Median (IQR) & $2(2-2)$ & $2(2-2)$ & $0.809^{\#}$ & 0.423 & NS \\
\hline & Range & $1-3$ & $1-2$ & & & \\
\hline
\end{tabular}

$\mathrm{P}$ value $>0.05:$ Not significant; $\mathrm{P}$ value $<0.05$ : Significant $\mathrm{P}$ value $<0.01$ : Highly significant

test value: \# Mann -Whitney test

Table 4: Comparison between two groups in terms of side effects

\begin{tabular}{|c|c|c|c|c|c|c|}
\hline \multicolumn{2}{|c|}{ Side effects } & \multirow{2}{*}{$\begin{array}{l}\text { Group D } \\
\text { No. }=\mathbf{2 0} \\
\end{array}$} & \multirow{2}{*}{$\begin{array}{l}\text { Group P } \\
\text { No. }=\mathbf{2 0}\end{array}$} & \multirow{2}{*}{ Test value* } & \multirow[t]{2}{*}{ P-value } & \multirow[t]{2}{*}{ Sig. } \\
\hline \multirow{3}{*}{ Bradycardia } & & & & & & \\
\hline & No & $10(50.0 \%)$ & $17(85.0 \%)$ & 5.584 & 0.018 & $S$ \\
\hline & Yes & $10(50.0 \%)$ & $3(15.0 \%)$ & & & \\
\hline \multirow[t]{2}{*}{ Hypotension } & No & $16(80.0 \%)$ & $9(80.0 \%)$ & 5.227 & 0.022 & $\mathrm{~S}$ \\
\hline & Yes & $4(20.0 \%)$ & $11(55.0 \%)$ & & & \\
\hline \multirow[t]{2}{*}{ Resp complication } & No & $18(90.0 \%)$ & $12(60.0 \%)$ & 4.800 & 0.028 & $\mathrm{~S}$ \\
\hline & Yes & $2(10.0 \%)$ & $8(40.0 \%)$ & & & \\
\hline \multirow[t]{2}{*}{ Endoscopist satisfaction } & No & $6(30.0 \%)$ & $10(50.0 \%)$ & 1.667 & 0.197 & NS \\
\hline & Yes & $14(70.0 \%)$ & $10(50.0 \%)$ & & & \\
\hline
\end{tabular}

$\mathrm{P}$ value $>0.05:$ Not significant; $\mathrm{P}$ value $<0.05$ : Significant; $\mathrm{P}$ value $<0.01$ : Highly significant

test value $\bullet$ : Independent t-test; *: Chi-square test

\section{DISCUSSION}

Colonoscopy is a diagnostic and therapeutic procedure that visualizes the rectum, colon, and a section of the terminal ileum to be examined and treated. No sedation, moderate sedation, or heavy sedation are all options for sedation during a colonoscopy ${ }^{(10)}$. In a colonoscopy, sedation can give adequate treatment and aid in the completion of the procedure. Appropriate sedation during surgery helps to reduce anxiety, pressure, the risk of complications, and enhance patient compliance, all of which can help to improve colonoscopy success rates and patient satisfaction ${ }^{(11)}$. The best agents for conscious sedation during endoscopic operations are still being researched, and dexmedetomidine studies have become more common ${ }^{(12)}$. Dexmedetomidine is a new drug of high-selectivity $\alpha_{2}$-adrenergic receptor agonist that causes drowsiness, memory loss, sympathetic and analgesic effects (11). Because of its sympatholytic effect due to its action on the $\alpha 2$ adrenoreceptor, it is linked to a decrease in HR (12). Propofol has sedative and hypnotic effects facilitated by $\mathrm{y}$-aminobutyric acid receptor without analgesic effect. Also, it carries a risk of rapid onset of deep sedation that causes respiratory or cardiovascular depression ${ }^{(13,14)}$.

The purpose of this study was to differentiate the effects of intravenous dexmedetomidine and propofol as conscious sedative agents used in colonoscopy. It has been carried out on two groups of patients: one group 
was taken initial loading dose of dexmedetomidine 1 $\mu \mathrm{g} / \mathrm{kg}$ IV for $10 \mathrm{~min}$ then received propofol $0.5 \mathrm{mg} / \mathrm{kg}$, after that a continuous IV infusion of dexmedetomidine $0.2-0.8 \mu \mathrm{g} / \mathrm{kg} / \mathrm{h}$ was received and the other was taken initial loading dose of propofol $2 \mathrm{mg} / \mathrm{kg} \mathrm{IV}$, followed by a continuous IV infusion of propofol $25-100 \mu \mathrm{g} / \mathrm{kg} / \mathrm{min}$ till the end of the colonoscope to investigate the hemodynamic parameters( $\mathrm{HR}, \mathrm{MAP}$, and $\mathrm{O}_{2}$ saturation), assessment, the level of sedation as measured by the Ramsay Sedation Score, surgeon satisfaction and any complications. In our study, we found no differences between propofol and dexmedetomidine regarding demographic data, but the propofol group had risks of hypoxia and hypotension rather than the dexmedetomidine group which had risks of bradycardia. These results were in agreement with Akarsu Ayazoğlu et al. ${ }^{(15)}$, Ding et al. ${ }^{(16)}$, Ji et al. ${ }^{(17)}$, and Wang et al. ${ }^{(18)}$, who discovered a lower heart rate in subjects given dexmedetomidine, but the values were generally greater than 50 beats/min and did not necessitate the administration of medications to treat bradycardia. These results were in disagreement with Edokpolo et al. ${ }^{(19)}$, who stated that there was no statistically significant difference between the two groups in the occurrence of sustained bradycardia or apnea. Also, Jalowiecki et al. ${ }^{(20)}$, had suggested the use of dexmedetomidine be restricted due to its side effects, as hemodynamic instability or prolonged recovery. There were conflicting reports on dexmedetomidine's respiratory effects. Belleville et al (21), showed a significant decrease was reported. This conflict is thought to be the result of either physiologic reactions caused by the arousal phenomenon or the use of boluses in these studies, which may have resulted in sustained and higher concentrations. In the current study, we discovered no significant difference between the two groups as regarded RSS in the preoperative, intraoperative, and 2 hours postoperative period but in the PACU "1 hour post-operative", when compared to group $\mathrm{P}$, there was a significantly lower in group D. Akarsu Ayazoğlu et al. ${ }^{(15)}$, found that sedation in the dexmedetomidine group, was efficient and the RSS between 5 and $25 \mathrm{~min}$ after the induction was significantly increased than the other groups which was related to its synergistic effects with propofol. Regarding endoscopist satisfaction showed a nonstatistically significant difference between the two groups. Nonetheless, the endoscopist in the $\mathrm{P}$ group was less satisfied (10 patients) when compared to (6 patients) in group D (as a cause of increased tendency to administer propofol infusion dose due to restlessness. Akarsu Ayazoğlu et al. (15), found that after the procedure, patient and endoscopist satisfaction was high in all groups.

\section{CONCLUSION}

The combination of dexmedetomidine with a low dose of propofol resulted in greater conscious sedation and adequate endoscopist satisfaction than propofol alone among the patient's undergoing colonoscopy. However, the heart rate should be regularly monitored in those patients.

Acknowledgments: The authors would like to thank all of the patients who agreed to participate in the study.

Ethics approval and consent to participate: This prospective, randomized, double-blinded study was carried out in the department of hepato-gastroenterology and infectious diseases department at Al-Zahra university hospital after approval from the hospital ethical committee under the registration number (2021111130) and obtaining patients signed informed consent.

Funding statement: The authors, not a funding institute or a firm, funded this study.

Conflict of interest: There are no competing interests declared by the authors. Authors' contributions: the research was conceived by AIF\& GAE, who also collaborated on its design. AIF\&SMK was in charge of data collecting, capturing, and processing. The data analysis was coordinated by GAE\&AME. The final manuscript was read and approved by all writers.

\section{REFERENCES}

1- Hazewinkel Y \& Dekker E. Colonoscopy, basic principles, and novel techniques, Nat. Rev. Gastroenterol. Hepatol. 2011; 8: 554564.

2- Karanth H, Murali S, Koteshwar R, Shetty V, Adappa K. Comparative study between propofol and dexmedetomidine for conscious sedation in patients undergoing outpatient colonoscopy. Anesthesia, essays and researches. 2018; 12(1):98-102.

3- Haselman MA. Dexmedetomidine: a useful adjunct to consider in some high-risk situation, AANA J; 2008; 76: 335-339

4- Riker RR, Shehabi Y, Bokesch PM, Ceraso D, Wisemandle W, Koura F, et al. Dexmedetomidine vs Midazolam for Sedation of Critically ill Patients: A Randomized Trial, JAMA; 2009; 301 (5): 489-99.

5- Somchai Amornyotin. Dexmedetomidine in gastrointestinal endoscopic procedures, World Journal of Anesthesiology 2016; 5(1): 1-14.

6- Muller S, Borowics SM, Fortis EA, Stefani LC, Soares G, Maguilnik I, et al. Clinical efficacy of dexmedetomidine alone is less than propofol for conscious sedation during ERCP. Gastrointestinal Endosc; 2008; 67:651-9. 
7- Ulmer BJ, Hansen JJ, Overley CA, Symms MR, Chadalawada V, Liangpunsakul S, et al. Propofol versus midazolam/fentanyl for outpatient colonoscopy: Administration by nurses supervised by endoscopists. Clin Gastroenterol Hepatol; 2003; 1:425-32,

8- Amornyotin S. Sedative and analgesic drugs for the gastrointestinal endoscopic procedure, J Gastroenterol Hepatol Res; 2014; 3: 1133 1144.

9- Wernli KJ, Brenner AT, Rutter CM, Inadomi JM. Risks Associated with Anesthesia Services During Colonoscopy. Gastroenterology; 2016; 150: 888.

10- Lichtenstein DR, Jagannath S, et al. Sedation and anesthesia in GI endoscopy.Standards of Practice Committee of the American Society for Gastrointestinal Endoscopy, Gastrointestinal Endosc; 2008; 68:815.

11- Liu W, Yu W, Yu H, Sheng M. Comparison of clinical efficacy and safety between dexmedetomidine and propofol among patients undergoing gastrointestinal endoscopy: a meta-analysis. Journal of International Medical Research. 2021; 49(7):113.

12- Srivastava N, Harjai M, Kumar S, Rai S, Malviya D, Tripathi M. A comparative study of dexmedetomidine and propofol infusion during monitored anesthesia care (MAC) in endoscopic cholangiopancreatography (ERCP): a randomized controlled trial. Ain-Shams Journal of Anesthesiology. 2021; 13(1):1-8.

13- Sato M, Horiuchi A, Tamaki M, et al. Safety and Effectiveness of Nurse-Administered Propofol Sedation in Outpatients Undergoing Gastrointestinal Endoscopy. Clin Gastroenterol Hepatol; 2018; 17: 1098-1104.

14- Secor T, Safadi AO and Gunderson S. Propofol Toxicity. Treasure Island (FL): StatPearls, 2021.
15- Akarsu Ayazoğlu T, Polat E, Bolat C, Yasar NF, Duman U, Akbulut S, Yol S. Comparison of propofol-based sedation regimens administered during colonoscopy. Rev Med Chil; 2013; 141:477-85.

16- Ding L, Zhang H, Mi W, Wang T, He Y, Zhang $\mathrm{X}, \mathrm{Ma} \mathrm{X}, \mathrm{Li} \mathrm{H}$. Effects of dexmedetomidine on the anesthesia recovery period and postoperative cognitive function of patients after robot-assisted laparoscopic radical cystectomy. Int J Clin Exp Med; 2015; 8:11388-95.

17- Ji J, Wang G, Sun K, Zhou G, Wang Z, Wang Y. Application of dexmedetomidine combined with propofol in patients undergoing painless colonoscopy for colonic polyps' resection under Narcotrend monitoring; 2015; 35: 2647.

18. Wang HM, Shi XY, Qin XR, Zhou JL, Xia YF. Comparison of dexmedetomidine and propofol for conscious sedation in inguinal hernia repair: A prospective, randomized, controlled trial. J Int Med Res; 2017; 45:533-9.

19- Edokpolo LU, Mastriano DJ, Serafin J, Weedon JC, Siddiqui MT, Dimaculangan DP. Discharge readiness after propofol with or without dexmedetomidine for colonoscopy: a randomized controlled trial. Anesthesiology. 2019; 131(2):279-86.

20- Jalowiecki P, Rudner R, Gonciarz M, Kawecki P, Petelenz M, Dziurdzik P. Sole use of dexmedetomidine has limited utility for conscious sedation during outpatient colonoscopy. Anesthesiology; 2005' 103: 26973.

21- Belleville JP, Ward DS, Bloor BC, Maze M. Effects of intravenous dexmedetomidine in humans. I. Sedation, ventilation, and metabolic rate. Anesthesiology; 1992; 77: 1125-33. 